\title{
EDITORIAL
}

\section{Procesos migratorios contemporáneos}

SOCIEDADEEQUIDAD

Contemporary Migration Processes

Nombre:

Filiación:

País:

Correo:

\author{
Belén Rojas Silva ${ }^{(1)}$ \\ Universidad de Paris Descartes \\ Francia \\ belen.rojas@gmail.com
}

Finalizar el año 2013 con un número de la revista «Sociedad y Equidad» dedicado al fenómeno migratorio no es en ningún caso un hecho anodino. Hace algunos meses conmemoramos 40 años del Golpe de Estado que provocó el mayor proceso migratorio de nuestra historia: el exilio.

Esfuerzos intelectuales y políticos, desde distintas miradas y sensibilidades, nos han aportado información heterogénea, y a veces contradictoria, acerca de este proceso. Lo anterior no sorprende, más bien es propio de las dificultades de la cuantificación de experiencias migratorias forzadas con distintas modalidades, alta dispersión y ausencia de información "oficial". Situación que se ve igualmente impactada por la diversidad y tensión de las memorias de sus protagonistas y analistas.

No obstante, hoy sabemos que el exilio chileno tuvo una cuantía entre 200.000 y 500.000 personas, cuyos orígenes y destinos fueron y son verdaderamente disímiles. Sabemos también que el retorno no fue fácil ni tampoco una opción evidente. Hoy coexisten las "comunidades" de chilenos en el extranjero (conformadas por antiguos exiliados y emigrantes) y en Chile, las segundas y terceras generaciones de los retornados, para quienes su primera experiencia migratoria es la llegada al país de origen de sus padres y/o abuelos.

En este sentido, los estudios acerca del exilio siempre han indicado que la posibilidad del retorno alteraba la vida de los exiliados y sus familias (Rebolledo, 2004). De una parte significaba el desarraigo de sus hijos y el riesgo de una reinserción incierta en un país que había cambiado sin ellos; por otra, el

\footnotetext{
${ }^{1}$ La autora es Licenciada en Antropología por la Universidad de Chile y estudiante de Doctorado en Sociología por la Universidad de Paris Descartes, Francia.
} 


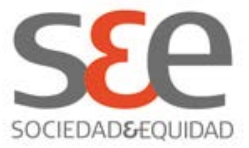

tránsito desde la categoría de exiliado a inmigrante en las sociedades de destino.

Sin embargo, aquello que no parecía evidente para los protagonistas de la experiencia, si lo era para el poder dictatorial. Nuestra actual legislación migratoria, que data de 1975, es hija del temor y rechazo a la posibilidad de que los opositores al régimen retornaran antes de lo previsto, mientras simultáneamente facilitaba su expulsión.

Hoy, estamos a la espera de la discusión parlamentaria acerca del nuevo Proyecto de Ley sobre Migración y Extranjería, concebido en democracia y en un escenario que parece avanzar hacia la transición entre un país que destaca por su trayectoria emigrante hacia un país receptor de inmigración. Debemos estar atentos a la evolución de este proyecto y su reglamento porque tal como planteó Helena Olea en relación al refugio en Chile, "un nuevo marco normativo no necesariamente es garantía de avances en la protección de derechos" (Olea, 2013:22)

Así, ya han surgido críticas en relación al énfasis del proyecto en la migración económica y la contratación de mano de obra ${ }^{2}$. En este sentido, el proyecto obviaría la multidimensionalidad de la experiencia migrante y su carácter, muchas veces, de instalación y familiar.

En relación a este nuevo contexto, el año 2013 nos ha más o menos sorprendido con la convocatoria y realización de una manifestación pública en contra de la inmigración. La marcha "contra inmigrantes" o "anti-inmigrantes" como la llamó la prensa nacional o "Recuperemos Antofagasta", como indicaba la convocatoria de sus organizadores; tuvo lugar en la II región el día 17 de octubre de 2013.

La región de Antofagasta ocuparía el tercer lugar de las regiones con mayor presencia de población extranjera ( 19.720 personas, cercana al 5\% de la población de la región ${ }^{3}$ ), antecedida por la I Región y la Región Metropolitana ${ }^{4}$. Un año antes de la convocatoria de esta marcha, Marcos González nos relataba que en la biografía de la región la migración ha sido una experiencia históricamente presente, no obstante la desigualdad con que ésta ha sido

\footnotetext{
${ }^{2}$ Al respecto véase, http:// ciperchile.cl/2013/ 06/21/ nueva-ley-de-migraciones-chilepide-mano-de-obra-y-vienen-personas/

${ }^{3}$ El porcentaje de población extranjera en la región esta aproximadamente un 3\% arriba del porcentaje nacional. Importante es también considerar que el número de inmigrantes en Chile se ha duplicado en los últimos 10 años.

${ }^{4}$ Al respecto, véase http:// www. latercera.com/ noticia/ nacional/ 2013/ 11/ 680-553170-

9-donde-estan-y-como-viven-los-extranjeros-en-chile. shtml
} 


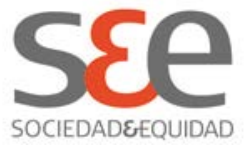

acogida de acuerdo a sus respectivos orígenes. Igualmente, González nos invitaba a reflexionar acerca de un futuro cercano donde las "contradicciones que son propias de ciudades como Antofagasta o Calama, tremendamente ricas pero con muchas deudas respecto a su población, comienzan con el tiempo a crisparse y no es aventurado pensar que algún día los inmigrantes sean el obj eto de ese enoj $0^{\prime \prime}$.

Así, la marcha parece el primer gesto organizado de ese enojo y también mucho más que eso. Aunque muchos y muchas respiramos aliviados ante la baja convocatoria de la manifestación, no podemos tornar la vista a la experiencia de construcción, y reproducción de diferencias y racialización de la que fue parte esta convocatoria; y las discusiones que en distintos espacios se generaron a partir de estas categorías.

Aquí no solo hubo una reproducción de la noción de migración irregular como delito, sino que también se movilizaron nociones propias de ejercicios de racialización. En primer lugar, basta observar el afiche de la manifestación para enfrentarse a la racialización de las apariencias y las prácticas en la distinción entre "nosotros" y los "otros". Si a eso le sumamos que cada caricatura de la inmigración apuntaba un arma o se mostraba como consumidor de drogas queda poco a la interpretación. En segundo lugar, debemos considerar que las demandas de control migratorio a la autoridad se apoyaban no solo en la idea "tradicional" de culpabilización por la ocupación de empleos considerados "nacionales", sino que además agregaba la responsabilidad de quiebres matrimoniales.

Tomar en consideración estos ejercicios de racialización significa avanzar en la comprensión de la dimensión más cotidiana de los racismos y a su vez la más difícil de asir. Igualmente significa ampliar el espectro de las relaciones que son posibles de concebir entre "nacionales" y "extranjeros" más allá del intercambio económico abordado por las legislaciones migratorias.

Al volcarnos a la vida cotidiana de los procesos migratorio, nos alejamos de las dicotomías con pretensiones de coherencia, para observar y auto observar cómo movilizamos categorías difusas, especificas y situadas en el ejercicio del racismo. La tarea pendiente es analizar cómo interaccionan contextualmente esas categorías, cómo se movilizan y a qué experiencia migratoria están dando lugar, teniendo siempre presente que hablar de migración es también mirarse al espejo. En esa experiencia cabemos y estamos todos, quienes se mueven y quienes no (Brah, 2011).

\footnotetext{
${ }^{5}$ Al respecto, véase http:/ / ballotage. cl/ 2012/ 07/ inmigracion-en-el-norte-de-chile-ylos-espacios-inciertos-de-nuestro-futuro-desarrollo/
} 


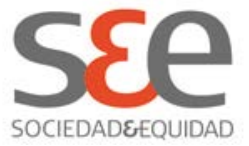

Así, ejemplos como la manifestación de Antofagasta nos recuerdan que si bien parecemos más abiertos a reconocer estrategias de inferiorización y exclusión en relación al racismo, no debemos olvidar que en éste coexisten desde la xenofilia a sutiles búsquedas en torno al deseo de lo extranjero, en un sentido amplio Así, no es aventurero pensar que estas categorías difusas de las que hablamos posicionan a otros, y nos posicionan, de distinta manera caso a caso. Igualmente, debemos estar atentos a los niveles de integración que promueven estas categorías, los cuales operan en más de una dirección. Es decir, las exclusiones no sólo imprimen coherencia al interior del grupo que genera una diferenciación excluyente, sino que también integran. Por esto en el caso de las inmigraciones, siempre es posible estar integrado "a" sin estar integrado "en".

Las tensiones enunciadas, que en ningún caso se circunscriben ni a la historia reciente ni a una región del país, nos confirman las limitaciones de una legislación que centre la relación con la inmigración en la actividad económica (y los permisos de residencia subyacentes). Si bien las proyecciones en relación a la migraciones son un ejercicio de alta complejidad, nuestro mínimo a considerar debe ser lo planteado por A. Sayad, es decir, que las migraciones movilizan historias, tradiciones, memorias, sentimientos, imaginarios, maneras de actuar. Igualmente creencias, códigos de interpretación y comunicación; estructuras sociales, políticas, mentales, etc. (Sayad, 1999). En síntesis, personas.

El sexto numeró de la Revista Sociedad y Equidad reúne un conjunto de investigaciones y reflexiones en torno a los procesos migratorios contemporáneos desde una multiplicidad de enfoques, contextos y metodologías. Los artículos y ensayos que aquí presentamos nos hablan de las distintas dimensiones y escenarios de la movilidad en nuestro continente, donde coexisten experiencias de migración interna, internacional y el transnacionalismo.

Se presentan aquí distintas voces, individuales y colectivas de la migración, e igualmente diferencias de género y generación, entre otras. Fenómenos como la feminización de las migraciones, las cadenas de cuidado, las organizaciones de migrantes y las segundas generaciones, son solo algunos de los aportes de éste número.

De la misma forma en que se interroga a los migrantes, también se interroga a los Estados e instituciones de acogida en su relación con los extranjeros. Sin dejar de lado además el análisis de informes y estadísticas de organismos internacionales y la producción y reproducción de conocimiento acerca de las migraciones en el marco de la academia. 


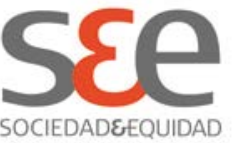

Como sabemos que hablar de migración siempre es, desde la más recatada de las perspectivas, hablar de al menos dos sociedades; entonces decimos que en este número conviven los procesos migratorios de Colombia, Argentina, México, Chile, España; pero también de Bolivia, Paraguay, Estados Unidos, Perú y Francia.

\section{Referencias Bibliográficas}

Brah, A. (2001). Cartografías de la diáspora. Identidades en cuestión. Madrid: Traficantes de Sueños.

Rebolledo, L. (2004). "Volver del Exilio". Revista Rocinante, № 64, febrero.

Sayad, A. (1999). La double absence. Des illusions de I'émigré aux souffrances de l'immigré. Paris : Editions Seuil.

Olea, H. (2003) "Ingreso y permanencia de extranjeros en Chile: elementos para la formulación de una política migratoria". Migraciones. Conferencia Internacional sobre Migraciones y Derechos Humanos: Estándares y Prácticas. Chile: Editorial Aun creemos en los sueños, 2013, pp. 21-26. 